$$
\begin{aligned}
& \text { CONF-9607126--10 } \\
& \text { CONF-960807--16 }
\end{aligned}
$$

DETERMINATION OF UNCONVERTED HDPE IN COAL/PLASTICS CO-LIQUEFACTION STREAM SAMPLES

G. A. Robbins

R. A. Winschel

F. P. Burke

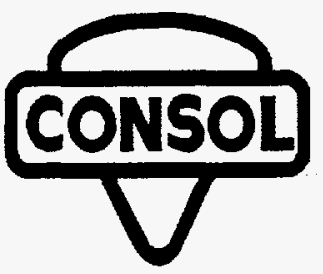

CONSOL Inc.

Research \& Development

4000 Brownsville Road

Library, PA 15129

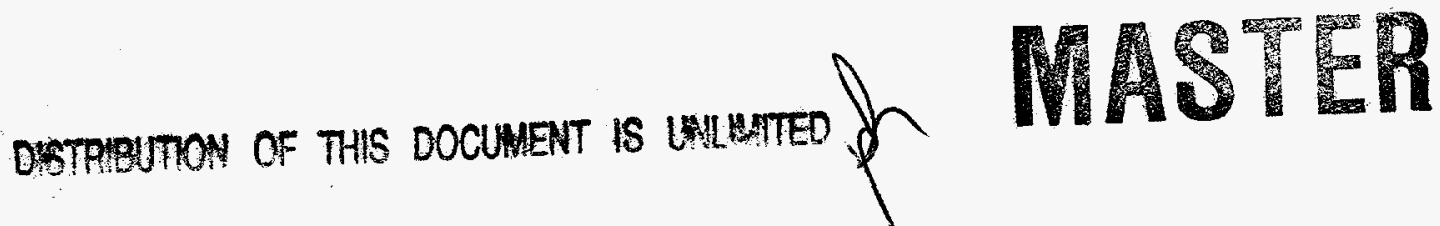




\section{DISCLAIMER}

This report was prepared as an account of work sponsored by an agency of the United States Government. Neither the United States Government nor any agency thereof, nor any of their employees, makes any warranty, express or implied, or assumes any legal liability or responsibility for the accuracy, completeness, or usefulness of any information, apparatus, product, or process disclosed, or represents that its use would not infringe privately owned rights. Reference herein to any specific commercial product, process, or service by trade name, trademark, manufacturer, or otherwise does not necessarily constitute or imply its endorsement, recommendation, or favoring by the United States Government or any agency thereof. The views and opinions of authors expressed herein do not necessarily state or reflect those of the United States Government or any agency thereof. 


\section{DISCLAIMER}

Portions of this document may be illegible electronic image products. Images are produced from the best available original document. 


\title{
DETERMINATION OF UNCONVERTED HDPE IN COAL/PLASTICS CO-LIQUEFACTION STREAM SAMPLES
}

\author{
Gary A. Robbins, Richard A. Winschel, and Francis P. Burke \\ CONSOL Inc. \\ Research \& Development \\ 4000 Brownsville Road \\ Library, PA 15129
}

KEYWORDS: coal liquefaction, coal/waste coprocessing, analysis

\begin{abstract}
INTRODUCTION
In several coal/plastics liquefaction runs performed by Hydrocarbon Technologies, Inc. (HTI), a substantial amount of incompletely converted high-density polyethylene (HDPE) was present in ashfree recycle resid streams when either the ROSE-SR unit was used in Run POC-2, or the pressure filter unit was used in Runs CMSL-8 and CMSL-9. This indicates that the HDPE is less reactive than coal at the liquefaction conditions used..$^{1-4}$ In these ash-free streams, there is no solid organic or inorganic material arising from the coal, and the incompletely converted HDPE can be recovered by extraction and filtration with tetrahydrofuran (THF) at room temperature. The HDPE (or HDPE-like material, which could also consist of heavy waxes) is THF insoluble. However, in ashy streams, there are both inorganic ("ash") and organic (unconverted coal) components present from liquefaction of the coal, that interfere with an easy and clean separation of the HDPE from the coal/plastics liquefaction stream sample. Therefore, CONSOL developed an analytical procedure for HDPE in the ashy stream samples based on extraction of HDPE from the sample using hot (150 ${ }^{\circ} \mathrm{C}$ ) decalin (decahydronaphthalene), in which the HDPE is soluble. The decalin extraction is both preceded and succeeded by extractions and washes with THF at room temperature, to remove the coal-derived components from the sample.
\end{abstract}

\section{EXPERIMENTAL}

HDPE Solubility and Filtration Tests. The first tests were performed to identify a suitable solvent and temperature for dissolution and recovery of the HDPE feedstock used in several HTI liquefaction runs. These experiments were conducted by heating beakers containing HDPE/solvent mixtures on a hot plate. The virgin HDPE, consisting of clear pellets, was supplied to HTI by Amco plastics, manufactured by BASF, mp $135^{\circ} \mathrm{C}$, and density $0.96 \mathrm{~g} / \mathrm{cc}^{5}$ It is essentially devoid of ash, sulfur, nitrogen, and oxygen. ${ }^{1}$ The decahydronaphthalene (decalin) was obtained from Aldrich Chemical Co., as anhydrous, $99+\%$ purity, consisting of a mixture of cis- and trans- isomers, and with bp 189$191^{\circ} \mathrm{C}$.

In mixed cresol at $\approx 150^{\circ} \mathrm{C}$, HDPE $(2 \mathrm{~g} / 25 \mathrm{~mL}$ cresol) melted, but did not dissolve. The HDPE readily dissolved in decalin at $125^{\circ} \mathrm{C}(2 \mathrm{~g} \mathrm{HDPE} / 50 \mathrm{~mL}$ decalin), forming a colorless solution. The HDPE-decalin solution at $125^{\circ} \mathrm{C}$ was pressure-filtered (about 7 psig nitrogen) through a Whatman no. 42 paper in a filtration apparatus which was heated to $145^{\circ} \mathrm{C}$. Hot decalin was used to rinse the beaker and filter paper, but some precipitated HDPE adhered to the beaker. The filtrate was cooled to room temperature. It then was pressure-filtered through Whatman no. 42 paper and washed with fresh, cool decalin. The filtrate was clear, and slightly yellow in color. The filter cake was dried in a vacuum oven at $60^{\circ} \mathrm{C}$. After drying, it still had a faint decalin odor. $91.6 \%$ of the original HDPE was recovered as a hard white solid. 
Tests of Extraction Sequence. It was expected that a THF wash would be needed to distinguish HDPE from other materials that may be extracted in hot decalin, since HDPE is completely insoluble in THF at room temperature. However, it was uncertain whether or not the decalin extraction step also should be preceded by THF-extraction to remove distillate and coal-derived residual components. A test was conducted in which aliquots of one sample were extracted using both test sequences. In the decalin-first procedure: 1) the sample was extracted and filtered with hot decalin, 2) the decalin extract was cooled to room temperature, 3) the precipitated solid HDPE was filtered and dried, 4) the tan-colored filter cake was washed with THF, and 5) all fractions were dried in the vacuum oven to remove solvent. In the THF-first procedure, the sample was extracted and filtered with THF at room temperature, and then steps 1 through 5 were followed. In this sequence, both the THF-soluble fractions obtained prior to and after decalin extraction were combined before solvent removal. Results of the extraction sequence tests are described below.

\section{RESULTS AND DISCUSSION}

Method Development and Validation. The solubility and filtration tests demonstrated that unreacted feed HDPE could be dissolved, filtered, and recovered in high yield (>90\% recovery). The results obtained using the two extraction sequences are quite similar (Table 1). Yields of the fractions were 34 to 39 wt \% HDPE (decalin-soluble, THF-insoluble), 58 to 62 wt \% THF solubles, and 3 wt \% THF and decalin insolubles. The similarity of the results provided overall validation of the method, and indicated that either method was probably adequate for routine analysis. HDPE products from both extractions had a similar tan color and coarse powdery appearance. However, the THF-first procedure minimizes the possibility of interferences, and the HDPE product was cleaner in appearance. FTIR spectra (not shown) indicated that the recovered HDPE fractions obtained by the two extraction sequences are similar to each other, and to the feed HDPE. Thus, these recovered decalin solubles appear to be essentially pure HDPE (or heavy n-paraffins, which may be indistinguishable from HDPE). The THF-first procedure requires an additional extraction step, but the total time required for the extraction steps is only about four hours. It was adopted as the routine method, a flow chart for which is shown in Figure 1. Solvent removal steps are not shown in the flow chart. This method was found to be easy to perform in a routine manner. Combined recoveries of the three fractions (THF solubles, HDPE, and THF/decalin insolubles) ranged from $98 \%$ to $105 \%$, averaging $102 \%$ in 19 tests using the method (this includes the decalin-first test described above). It is presumed that recoveries are biased high because of the difficulty in removing solvents (THF or decalin) from the recovered fractions. For routine use, the fraction percentages are reported on a normalized basis. Additional validation information was developed in conjunction with application of the extraction method to authentic samples from HTI Runs CMSL-8 and CMSL-9, and is described in sections to follow.

Application to Runs CMSL-8 and CMSL-9. The HDPE extraction method was applied to selected samples from HTI Runs CMSL-8 and CMSL-9 to characterize the samples and determine the fate of HDPE. ${ }^{2-4}$ The data were used for four purposes: 1) determine the amount of HDPE in the pressure filter cake (PFC) samples from periods in which coal and plastics were fed, 2) determine the degree of analytical interference from HDPE-like material produced from the coal, 3) determine the HDPE conversion for each of the periods of coal/plastics operation, and 4) develop a HDPE material balance around the solids separation unit (vacuum still or pressure filter, depending on run and operating period). ${ }^{2.4}$ The conditions in Runs CMSL-8 and CMSL-9 relevant to this discussion are given in Table 2. Solids separation operations in the HTI bench unit are conducted using either pressure filtration or vacuum distillation; characteristics of the bottoms and overhead streams from these two operations differ greatly. Sample streams relevant to this discussion are: 1) continuous atmospheric still bottoms (CASB), the flashed bottoms product of liquefaction and the feed to the solids separation device in use; 2) pressure filter liquid (PFL), the solids-free recycle stream; 3 ) 
pressure filter cake (PFC), the corresponding filter solids containing rejected insolubles; 4) vacuum still overheads (VSOH), the $524^{\circ} \mathrm{C}$ - distillate; and 5) vacuum still bottoms (VSB), the rejected 524 ${ }^{\circ} \mathrm{C}^{+}$resid and ash.

The extraction results (not shown) for Conditions 8-1 and 9-6 (coal feed only) show that little coalderived material reports as "HDPE" using this method. In samples of resid from CASB and of PFC from Condition 8-1 and 9-6, only 0.06 to $0.32 \mathrm{wt} \%$ of each sample reported as "HDPE". ${ }^{2.4}$ Extraction results from the coal/plastics operating periods show that with pressure filtration, little HDPE goes out in the PFC stream; instead, most of the HDPE is recycled in the PFL stream. During coal/plastics periods of Run CMSL-8 there was about 5 wt \% HDPE in the PFC stream, and 16 to 37 wt \% HDPE in the PFL stream. During coal/plastics periods of Run CMSL-9 there was about 2 wt \% HDPE in the PFC stream, and about $23 \mathrm{wt} \%$ HDPE in the PFL stream. ${ }^{4}$ CASB $454^{\circ} \mathrm{C}^{+}$resids from Conditions 8-2 through 8-5 were found to contain 15 to 62 wt \% HDPE; those from Conditions 9-7 through 9-9 were found to contain 9 to 35 wt \% HDPE. In Condition 9-7, there was 11 wt \% HDPE in the VSB sample (it is presumed that none is in the corresponding VSOH sample).

Material balances (based on a combination of CONSOL analytical results with HTI material balance data) for HDPE around the solids separation operations gave generally poor results (not shown, results ranged from $32 \%$ to $374 \%$ in Runs CMSL- 8 and CMSL-9). Corresponding ash balances based on CONSOL analytical data from the same samples ranged from $102 \%$ to $1264 \%$, i.e., more than twelve-fold over recovery. The poor ash balances indicated that the problem was not an analytical problem with the HDPE method, per se. We had observed that some CASB samples from Runs CMSL-8 and CMSL-9 were inordinately low in ash, and the sample integrity was suspect. We examined the percent total THF insolubles (THFI) obtained from two extraction procedures on two CASB sample types (whole or resid). Assuming robust extraction procedures, the THFI contents determined by different extraction procedures on the same sample should agree well. Using Method 1, (the decalin extraction method), the THFI content is the sum of THF/DI (THF and decalin insolubles) and HDPE fraction weight percentages. Using Method 2 (the THF extraction procedure that is our normal work-up procedure for liquefaction samples), the THFI content is the sum of unconverted coal and ash component weight percentages. As shown in Figure 2, the amount of THFI obtained by the two methods on two sample types (CASB $454^{\circ} \mathrm{C}^{+}$resid and whole CASB), shows considerable scatter for samples representing a particular run condition. These data thus confirm that a major problem may lie in obtaining good data from the CASB samples from coal/plastics operations at HTI. In contrast, we find that percent THF insolubles obtained by the decalin extraction method of VSB and PFC are very similar to those obtained by THF extraction of the same samples (Figure 3). These results indicate that there may be little problem with use of the decalin extraction data obtained from the VSB and PFC samples.

HDPE Conversion During Runs CMSL-8 and CMSL-9. Our original procedure for estimating HDPE conversions during Run CMSL-8 employed the simplifying assumption that the PFC contained no unconverted HDPE. ${ }^{2.3}$ At the time, we had no way of measuring the concentration of unconverted HDPE in solids-containing streams. We can now make these measurements directly with the hot decalin extraction procedure. The HDPE extraction results described above for samples from Runs CMSL-8 and CMSL-9 generally validate the original assumption that the PFCs contain no HDPE, because little HDPE (1 to 6 wt \%) was found in the PFC samples.

Both overall and single-pass conversions of HDPE are given by:

$$
\text { Conversion = [Mass of HDPE in - Mass of HDPE Out] } \times 100 / \text { [Mass of HDPE In], }
$$

where the masses of HDPE in and out are defined differently for overall conversion than for single- 
pass conversion. For overall conversion, the "mass of HDPE in" is the HDPE in the fresh feed, and the "mass of HDPE out" is summed from HDPE in any net product streams, such as PFL and PFC or VSB. For single-pass conversion, the "mass of HDPE in" is the sum of HDPE in the fresh feed and all recycle streams (such as CASB, PFL, and PFC or VSB), and the "mass of HDPE out" is the sum of HDPE in all of the gross product streams (such as CASB, PFL, and PFC or VSB). The results presented here for Run CMSL- 8 differ from those given previously, ${ }^{2,3}$ in that HDPE can be accounted for in more streams, whereas previously it could only be accounted in the fresh feed and PFL streams. Note that CASB can be accounted directly (if the HDPE content of CASB is measured), or it can be accounted as both PFL and PFC (or as VSB). Thus, it is possible to measure single-pass HDPE conversion with CASB as a recycle or product stream, even if the HDPE content of the CASB is not measured directly. Problems described above with use of the CASB data suggests that it may be better to use the PFL/PFC accounting approach, since the HDPE concentrations of PFC samples seem to be more reliable than those of CASB samples.

In Figure 4, the overall and single-pass conversions of HDPE in each period of Runs CMSL-8 and 9 that were evaluated are compared. The overall conversion of HDPE ranged from $69-86 \%$ during Run CMSL-9, comparable to those obtained for periods Conditions 8-2, 8-4, and 8-5. This was accomplished in spite of operation at a higher space velocity and without benefit of supported catalyst, but at higher liquefaction temperatures in Run CMSL-9. A high space velocity led to operating problems and low HDPE conversion in Condition 8-3. Higher conversion of HDPE in Condition 9-7, in which vacuum distillation and ashy recycle were used, relative to Conditions 9-8 and 9-9, in which pressure filtration and ash-free recycle were used, suggests that use of ashy recycle may increase HDPE conversion. In Figure 5, the overall HDPE conversions based on this direct measurement method for Run CMSL- 9 periods are compared with those estimated by $\mathrm{HTI}^{6}$ based on measured total feed conversions, and assumed fixed conversions of $88 \%$ for the coal, and $100 \%$ for all of the non-HDPE plastics. These two sets of results show fair to good overall agreement, for the overall run and for individual periods. HTl's model assumptions thus appear to apply to the combination of coal and plastics tested in Run CMSL-9.

\section{CONCLUSIONS}

A HDPE extraction method was developed that can be routinely applied to ashy coal/plastics coliquefaction stream samples. The method requires about four hours of operator and extraction time, with several hours of additional time needed for solvent removal from recovered fractions. The HDPE extraction method shows little interference from coal-derived material. Results from the HDPE extraction method show that during coal/plastics operations with pressure filtration, little HDPE goes out in the PFC stream; instead, most of the HDPE is recycled in the pressure-filter liquid (PFL) stream. HDPE extraction results were combined with material balance data to calculate HDPE balances and conversions during Runs CMSL-8 and CMSL-9. HDPE extraction results obtained from PFC and VSB samples appear to be reliable, but those from CASB samples are generally poor, either from sampling or analytical inconsistencies. The overall conversion of HDPE ranged from 69$86 \%$ during Run CMSL-9, comparable to those obtained for most periods of Run CMSL-8. Run CMSL-9 results suggest that ashy recycle may increase HDPE conversion. Overall HDPE conversions determined by CONSOL are consistent with those estimated by HTI for Run CMSL-9.

\section{FUTURE WORK}

The HDPE concentration data provided by this method can provide a basis for consideration of kinetics of HDPE conversion, and in development of improved processing strategies. In runs following CMSL-9, HTI's feedstocks for co-liquefaction have included municipal solid waste (MSW) plastics and petroleum resid, in various combinations with and without coal. The HDPE extraction method provides a potential means to determine HDPE concentration in mixed MSW feeds. A potential difficulty for the method is interference from petroleum resid. Since heavy waxes may 
behave like HDPE in terms of solubilities in decalin and THF, it may be more difficult to distinguish petroleum resid and HDPE than to distinguish coal-derived material and HDPE. We will continue to apply this characterization method to samples from appropriate streams in subsequent runs in which HDPE was fed.

\section{ACKNOWLEDGMENTS}

Samples and other information were provided by Dr. Vivek Pradhan of HTI. This work was sponsored by the U.S. Department of Energy under contract no. DE-AC22-94PC93054.

\section{REFERENCES}

1. Robbins, G. A.; Brandes, S. D.; Winschel, R. A.; Burke, F. P. "A Characterization and Evaluation of Coal Liquefaction Process Streams, Quarterly Technical Progress Report October 1 through December 31, 1994", DOE/PC 93054-10, May 1995.

2. Robbins, G. A.; Brandes, S. D.; Winschel, R. A.; Burke, F. P. "A Characterization and Evaluation of Coal Liquefaction Process Streams, Quarterly Technical Progress Report April 1 through June 30, 1995", DOE/PC 93054-18, September 1995.

3. Robbins, G. A.; Brandes, S. D.; Winschel, R. A.; Burke, F. P. "Characteristics of Process Oils from HTI Coal/Plastics Co-Liquefaction Runs", Proceedings of the DOE Coal Liquefaction and Gas Conversion Contractors Review Conference, August 29-31, 1995, Pittsburgh, PA.

4. Robbins, G. A.; Brandes, S. D.; Winschel, R. A.; Burke, F. P. "A Characterization and Evaluation of Coal Liquefaction Process Streams, Quarterly Technical Progress Report October 1 through December 31, 1995", DOE/PC 93054-25, May 1996.

5. Comolii, A. G. "Results of Recent POC Run at HRI on Waste/Coal Coprocessing", Proceedings of the PETC/DOE Workshop "Waste/Coal Coprocessing", Pittsburgh, PA, September 9, 1994.

6. V.R. Pradhan, personal communication, and HTI reports covering Runs CMSL-8 and CMSL9 under DOE Contract No. DE-AC22-93PC92147.

TABLE 1. TEST OF THF AND DECALIN EXTRACTION SEQUENCE IN A TEST SAMPLE

\begin{tabular}{||l|c|c||}
\hline \multirow{2}{*}{ Fraction } & \multicolumn{2}{|c|}{$\begin{array}{c}\text { Fraction wt \% of Sample (454 }{ }^{\circ} \mathrm{C}^{+} \text {Resid from CAS Bottoms } \\
\text { Sample, Period 38 of Run CMSL-9) }\end{array}$} \\
\cline { 2 - 3 } & $\begin{array}{c}\text { Decalin Extraction First - } \\
\text { Unnormalized (Normalized) }\end{array}$ & $\begin{array}{c}\text { THF Extraction First - } \\
\text { Unnormalized (Normalized) }\end{array}$ \\
\hline THF/Decalin Insolubles & $2.91(2.77)$ & $3.59(3.46)$ \\
\hline THF Solubles & $61.0(58.2)$ & $64.3(62.1)$ \\
\hline $\begin{array}{l}\text { Decalin Solubles } / \text { THF } \\
\text { Insolubles (HDPE) }\end{array}$ & $40.9(39.0)$ & $35.7(34.4)$ \\
\hline Recovery & $104.8(100.0)$ & $103.6(100.0)$ \\
\hline
\end{tabular}


TABLE 2. SUMMARY OF CONDITIONS FROM COAL AND COALIPLASTICS OPERATIONS IN HTI RUNS CMSL-8 AND CMSL-9

\begin{tabular}{|c|c|c|c|c|}
\hline $\begin{array}{l}\text { Run and } \\
\text { Condition } \\
\text { Number }\end{array}$ & $\begin{array}{c}\text { Run } \\
\text { Period } \\
\end{array}$ & $\begin{array}{c}\% \text { Plastics in Fresh } \\
\text { Feed (Remainder is } \\
\text { Coal) }\end{array}$ & $\begin{array}{c}\% \text { HDPE in Fresh } \\
\text { Feed }\end{array}$ & $\begin{array}{c}\text { Recycle/Solids } \\
\text { Separation Methods }\end{array}$ \\
\hline \multicolumn{5}{|c|}{$\begin{array}{l}\text { CMSL-8 }(227-85) \\
\text { Coal: Crown II Mine, III. } 6 \text { Seam } \\
\text { Mixed Plastics: HDPE, PS, PET } \\
\text { Catalysts: Shell } 317 / 1 \text { st Reactor }\end{array}$} \\
\hline $8-1$ & 6 & 0 & 0.0 & Ash-Free/Pres. Filt. \\
\hline $8-2$ & 11 & 25 (mixed) & 12.5 & Ash-Free/Pres. Filt. \\
\hline $8-3$ & 16 & 25 (mixed) & 12.5 & Ash-Free/Pres. Filt. \\
\hline $8-4$ & 20 & 33 (mixed) & 16.5 & Ash-Free/Pres. Filt. \\
\hline $8-5$ & $22 / 23$ & 33 (HDPE) & 33.0 & Ash-Free/Pres. Filt. \\
\hline \multicolumn{5}{|c|}{$\begin{array}{l}\text { CMSL-9 (227-87) } \\
\text { Coal: Black Thunder Mine, Wyodak \& Anderson Seams } \\
\text { Mixed Plastics: HDPE, PP, PS } \\
\text { Catalysts: Dispersed-Only, Mo ( } 100-300 \mathrm{ppm}) \text { and Fe ( } 10000 \mathrm{ppm}) \\
\text { Temperatures: } T_{2} T_{2}+\text { ca. } 10^{\circ} \mathrm{C} \text { in } 1 \mathrm{st} / 2 \text { nd Liquefaction Reactors, } T_{2}>T_{1} \text { in CMSL-8 }\end{array}$} \\
\hline $9-6$ & 29 & 0 & 0 & Ashy Nac. Still \\
\hline $9-7$ & 34 & 33 (mixed) & 13 & AshyNac. Still \\
\hline $9-8$ & 38 & 33 (HDPE) & 33 & Ash-Free/Pres. Filt. \\
\hline $9-9$ & 41 & 50 (mixed) & 20 & Ash-Free/Pres. Filt. \\
\hline
\end{tabular}




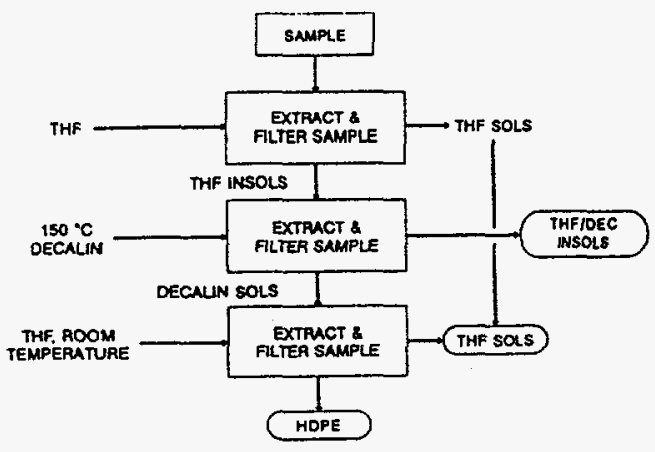

Figure 1. Flow Chart of Hot Decalin Extraction Method to Recover HDPE from Coal/Plastics Co-Liquefaction Samples.

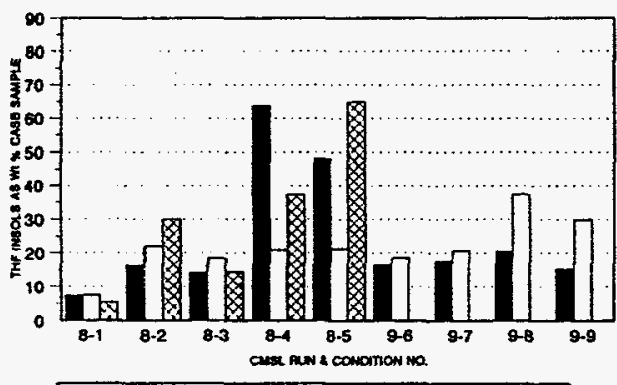

Wethod 1. Resid $\square$ Method 2, Resid B Method 2, Whole

Figure 2. THF Insolubles Concentration in CASB Samples from HTI Runs CMSL-8 and CMSL -9 as Measured by Two Extraction Procedures, Showing Poor Agreement.

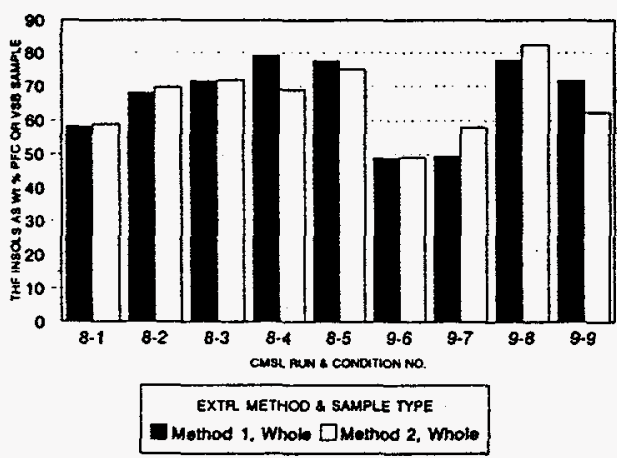

Figure 3. THF Insolubles Concentration in PFC and VSB Samples from HTI Runs CMSL8 and CMSL- 9 as Measured by Two Extraction Procedures, Showing Good Agreement.

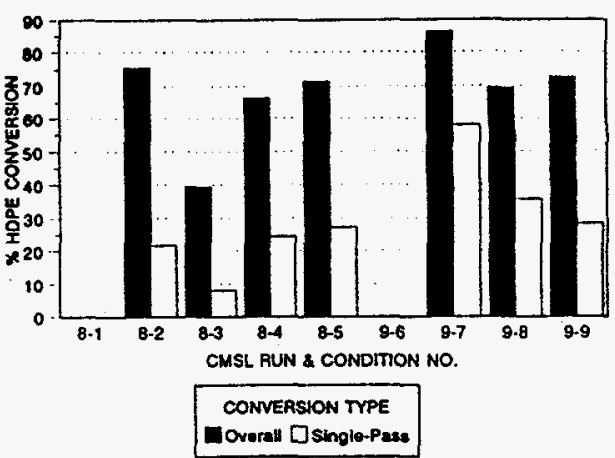

Fiqure 4. Overall and Single-Pass Conversion of HDPE in HTI Runs CMSL-8 and CMSL-9.

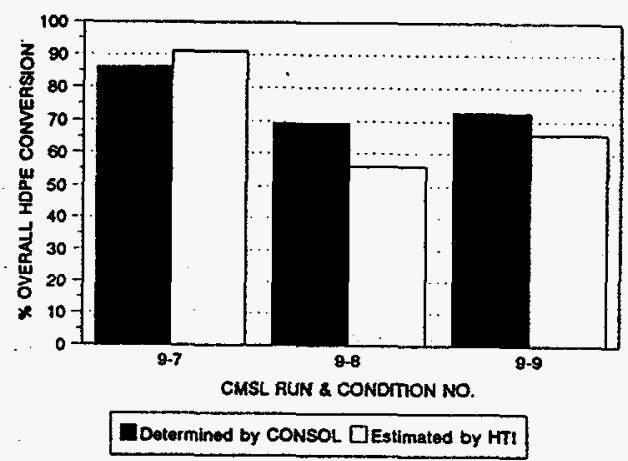

Figure 5. A Comparison of CONSOL (Determined) and HTI (Estimated) Overall Conversion of HDPE in HTI RUn CMSL-9. 